\title{
In Situ Stress State in Mainland China
}

\author{
FANGQUAN LI ${ }^{1}$
}

\begin{abstract}
In situ stress measurements are one of the important methods for studying the recent tectonic stress field and stress state. In this paper, the stress state and variation of stresses with depth in Mainland China are presented and analyzed on the basis of in situ stress data measured by both hydrofracturing and overcoring techniques.
\end{abstract}

Key words: Stress state, variation of stresses with depth, in situ stress measurements.

\section{Introduction}

In situ stress measurements provide important data for the study of the recent tectonic stress field and stress state of the crust. Stress measurements are of considerable interest in terms of geodynamics as well as in earthquake studies. In addition, they have become increasingly important in such fields as the design of mine tunnels and other underground structures, nuclear waste isolation, development of oil-gas fields, geothermal energy extraction and stability of hydroelectric facilities.

The stress state and the variation of stresses with depth in Mainland China are discussed on the basis of in situ stress data obtained by both hydrofracturing and overcoring techniques.

\section{Data of the in situ Stress Measurements in China}

During the past twenty years we have carried out a series in situ stress measurements using both overcoring and hydrofracturing methods in various regions of Mainland China (Table 1) (LI et al., 1979, 1986). As a result, we obtained a preliminary result concerning the stress state and the variation of stresses with depth in the upper crust of Mainland China.

\footnotetext{
' Institute of Crustal Dynamics, SSB, Beijing 100085, China.
} 


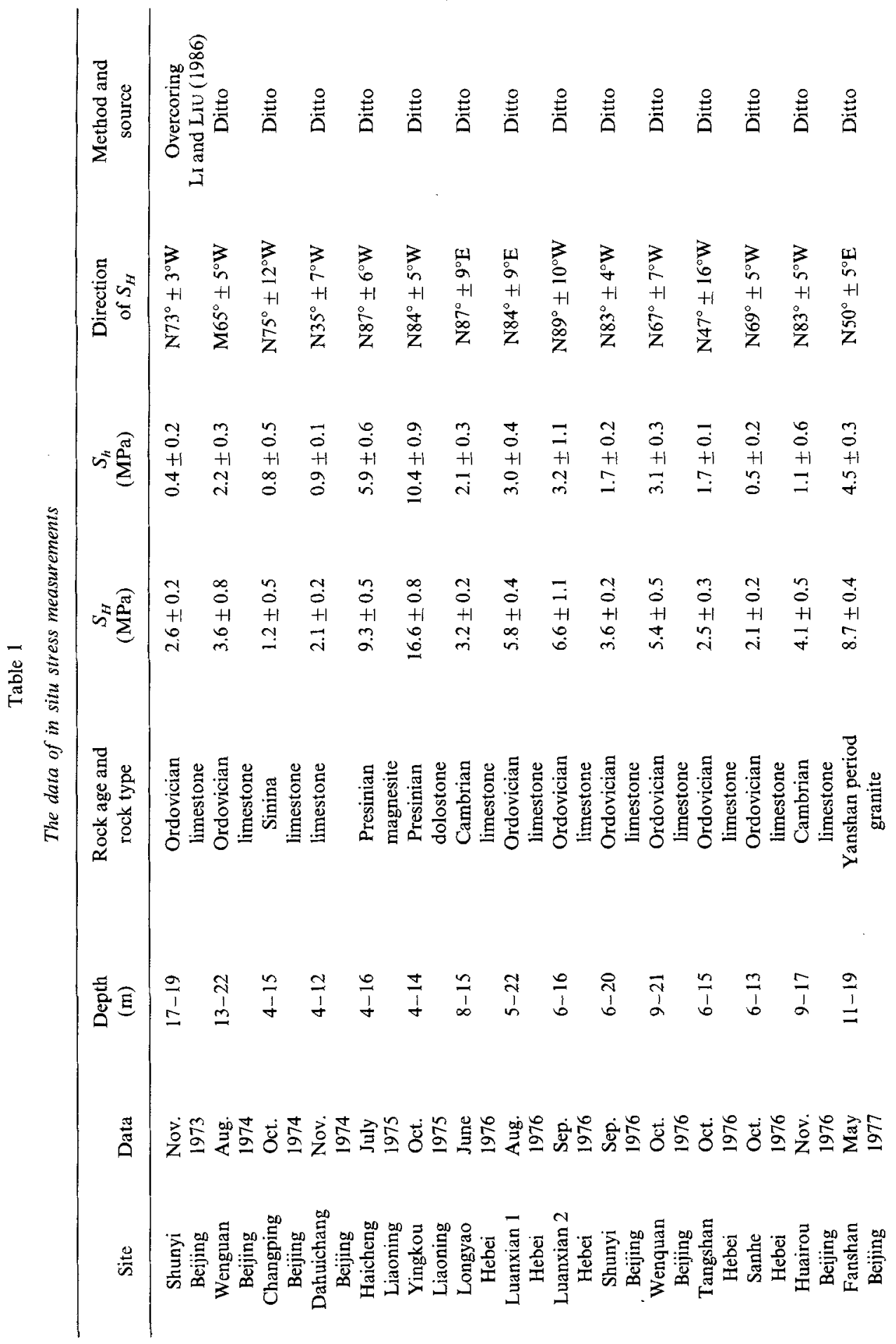




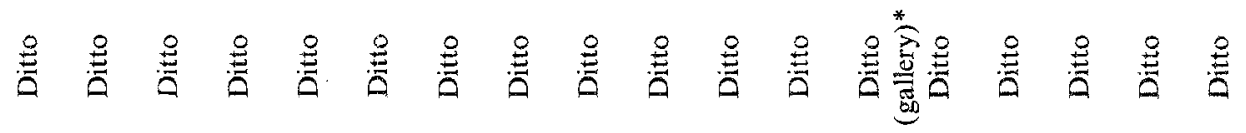

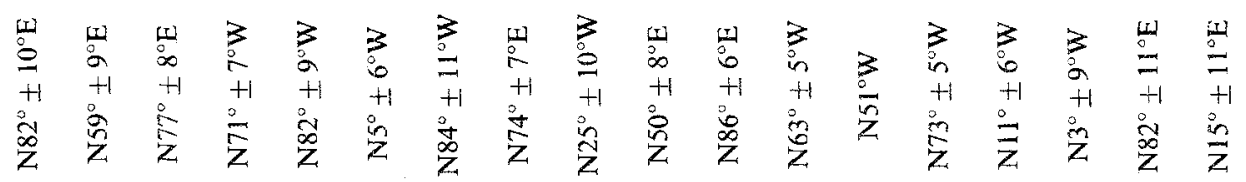

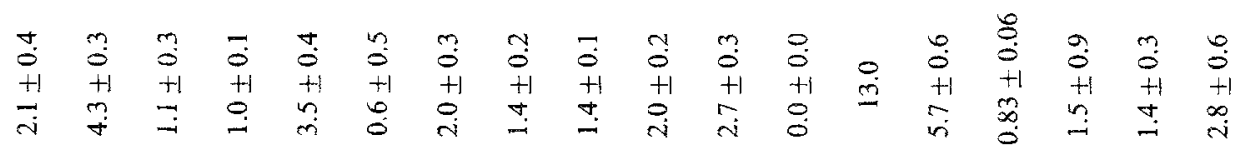

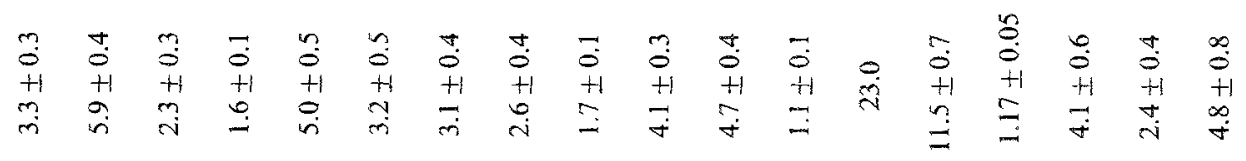

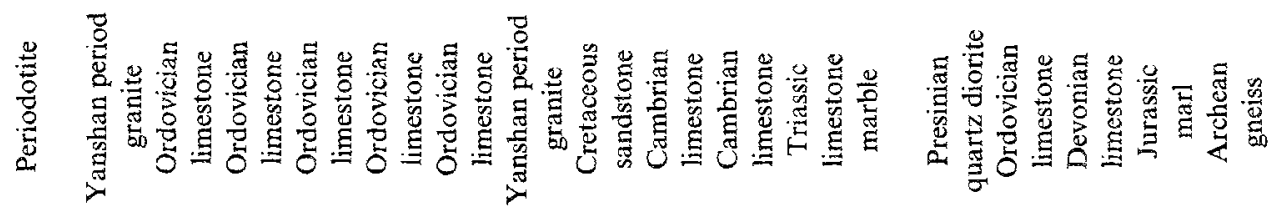

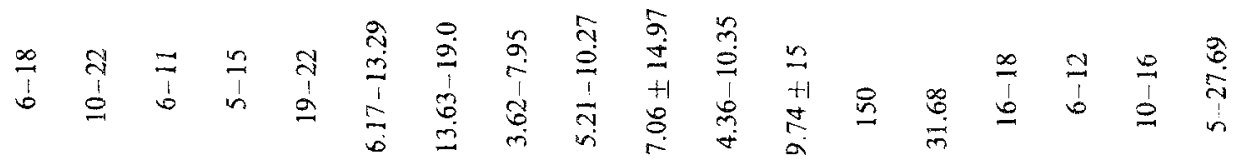

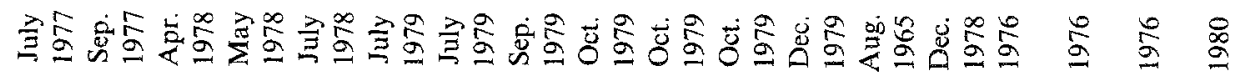

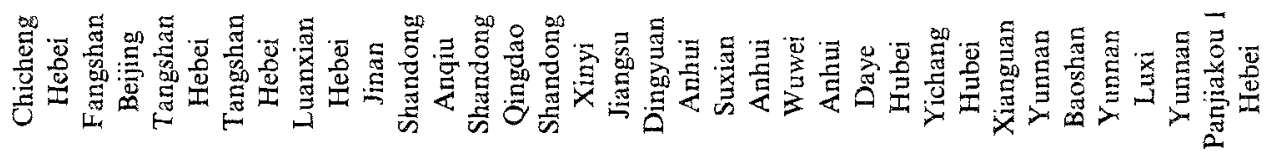




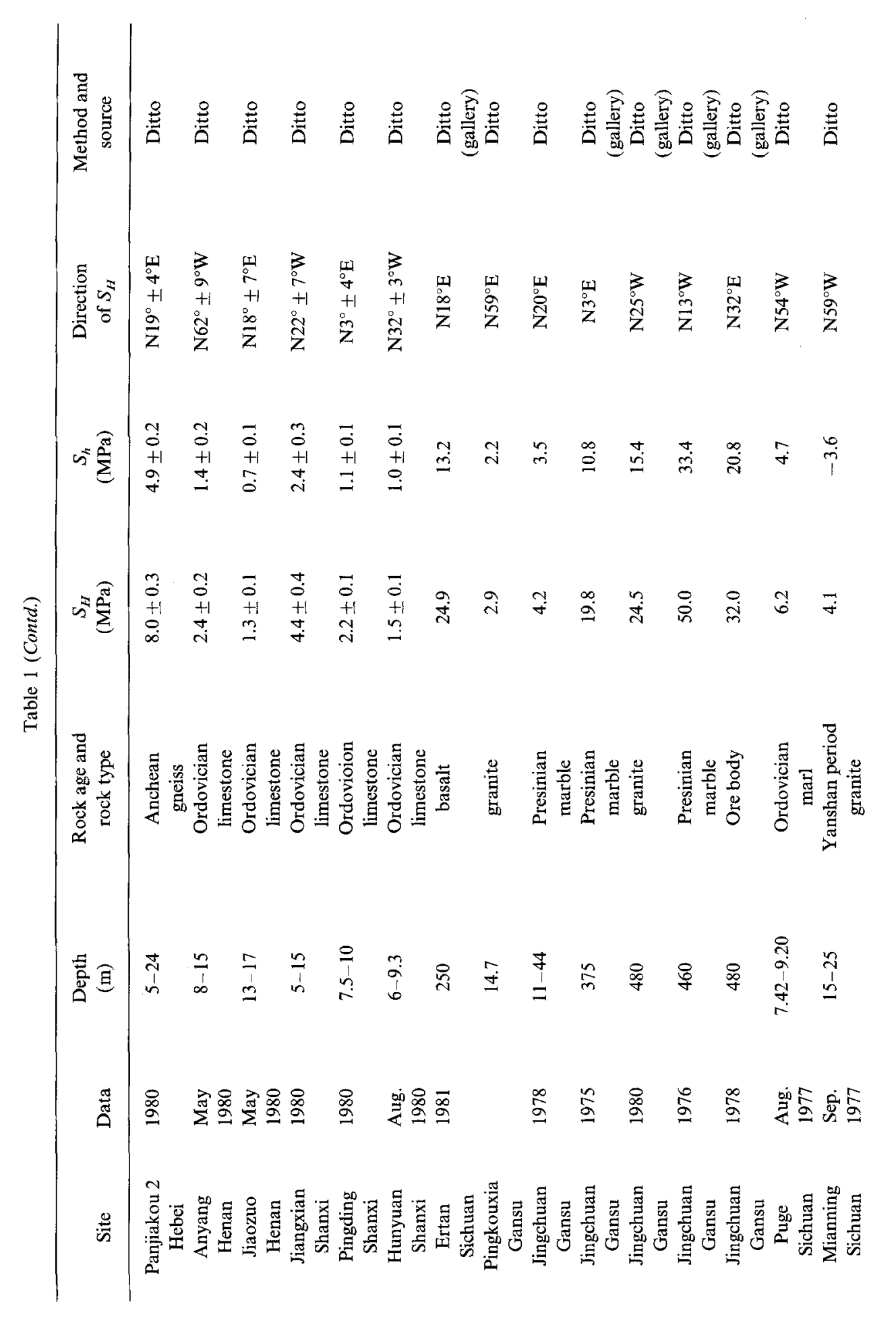




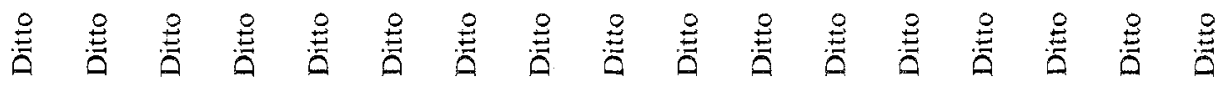

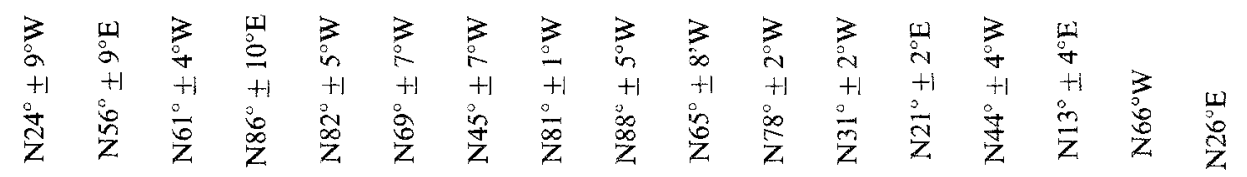

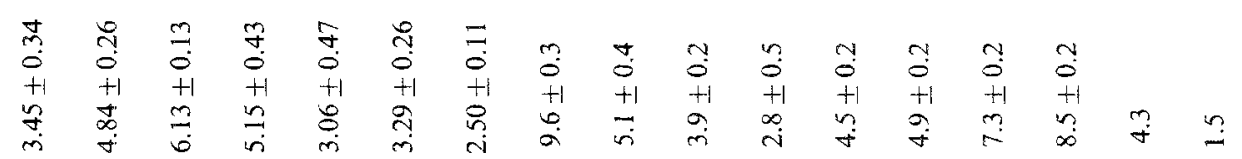

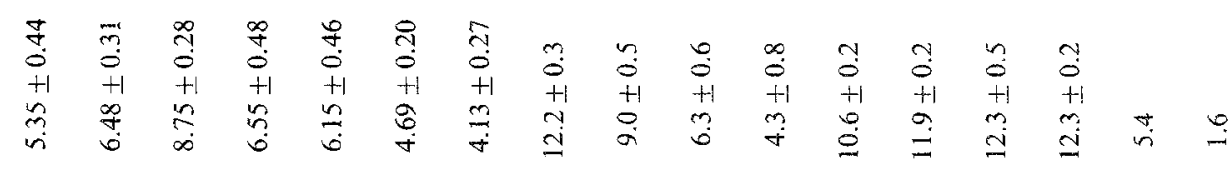

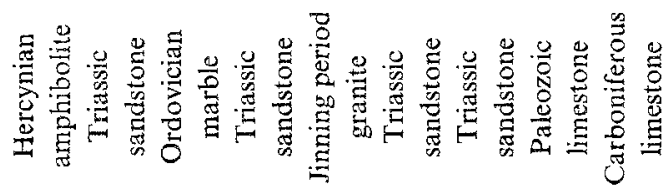

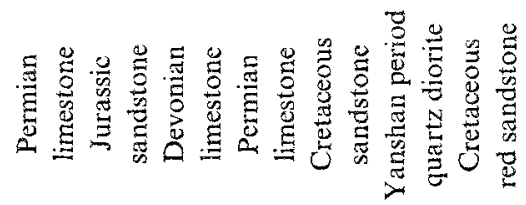

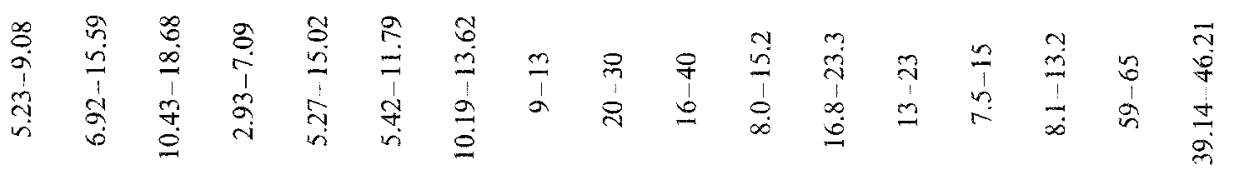

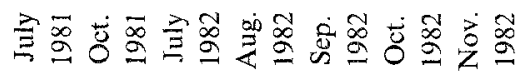

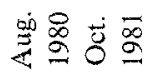

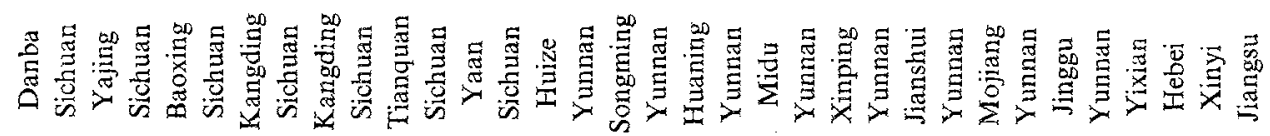




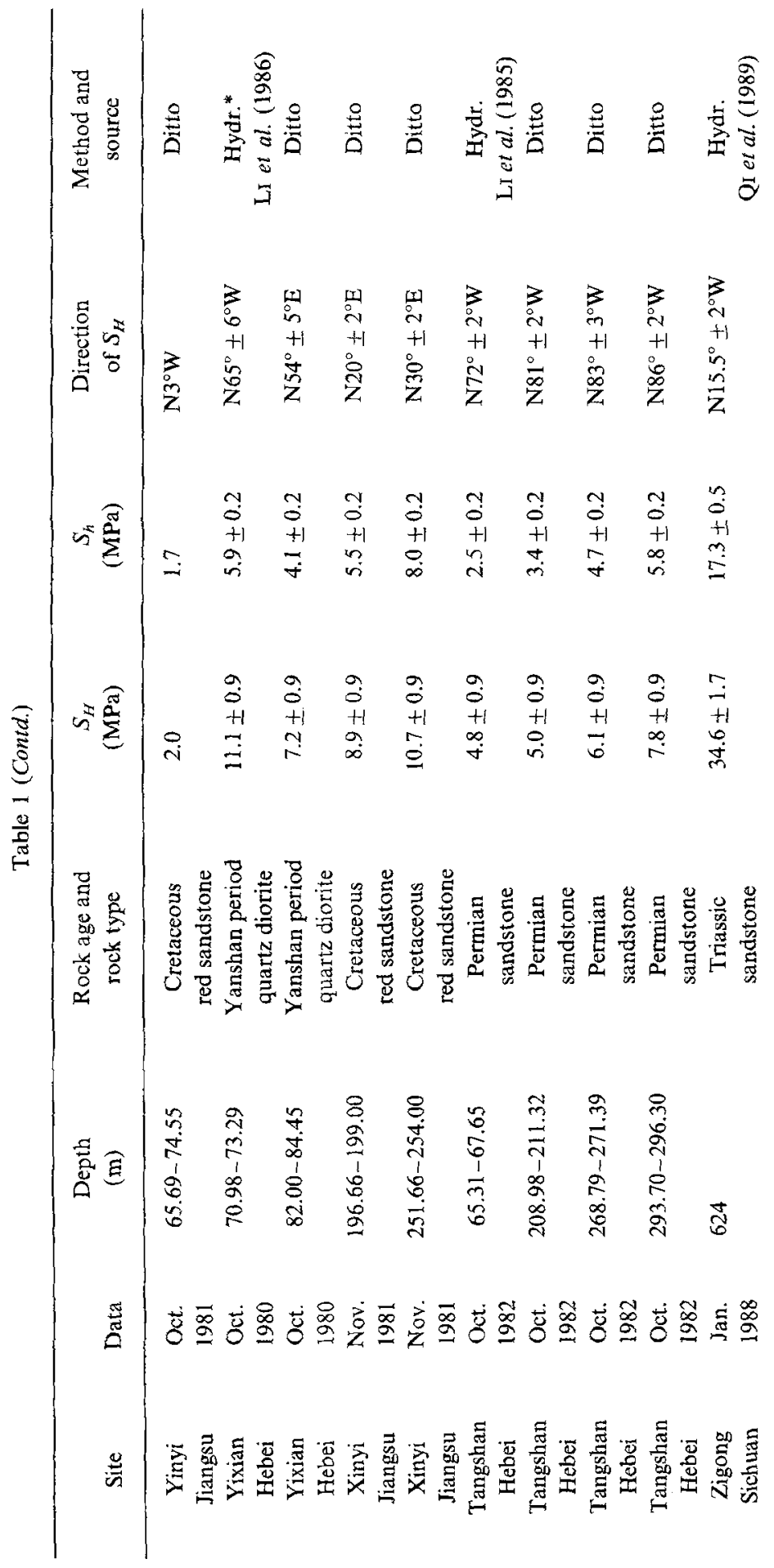




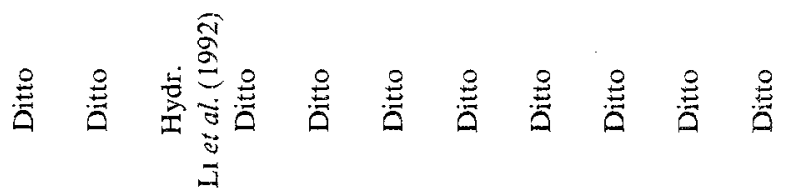

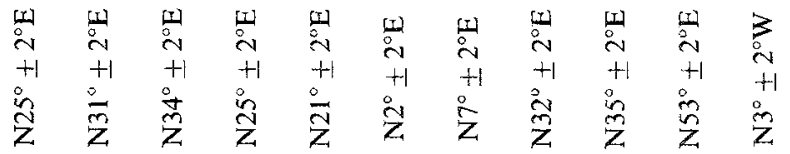

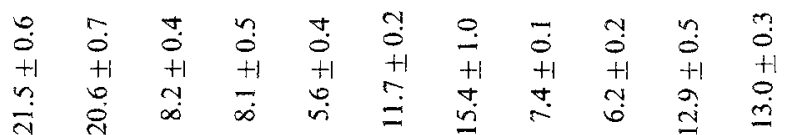

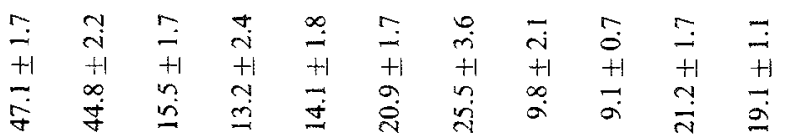

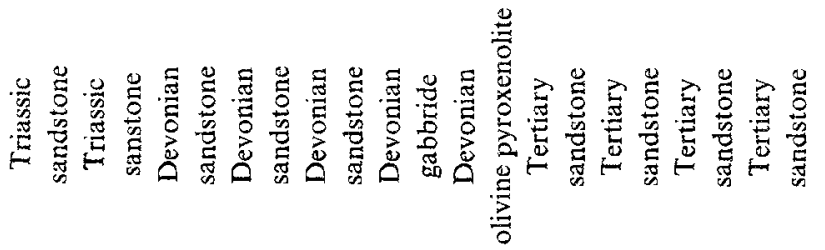

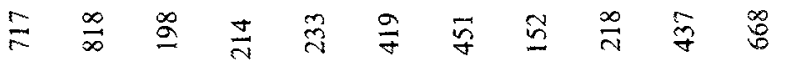

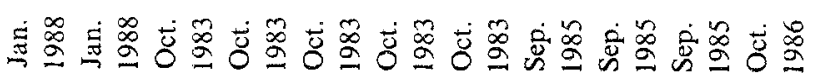




\section{The Stress State in Mainland China}

\subsection{The Variation of Horizontal Principal Stresses with Depth}

The rate of increase of the horizontal principal stresses with depth in China is generally greater than that of the vertical stresses.

All of these results are summarized in Figure 1. For these data except for Tangshan, we have

$$
\begin{array}{ll}
S_{H}=(4.5 \pm 2.5)+0.049 H & (\mathrm{MPa}) \\
S_{h}=(1.5 \pm 1.0)+0.030 H & (\mathrm{MPa})
\end{array}
$$

where $S_{H}$ and $S_{h}$ are the maximum and minimum horizontal compressive stresses, respectively, $H$ is the depth in meters, and errors correspond to the shaded area in Figure 1.

\subsection{The Variations of the Major Horizontal Shear Stresses with Depth}

The variations of the major horizontal shear stresses, $\tau=\left(S_{H}-S_{h}\right) / 2$, with depth are shown in Figure 2, which are characterized by regional variation.

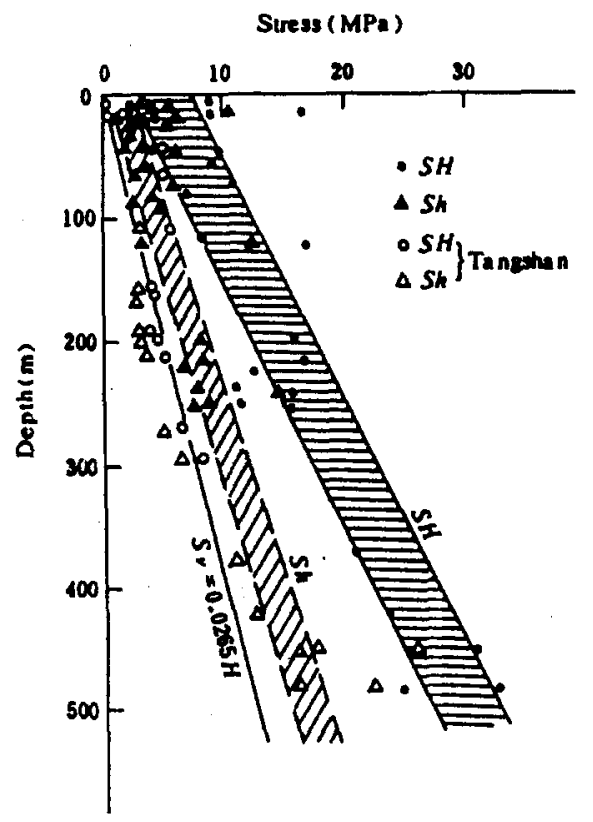

Figure 1

The horizontal stresses as a function of depth (open circles and triangles obtained from the Tangshan region). 


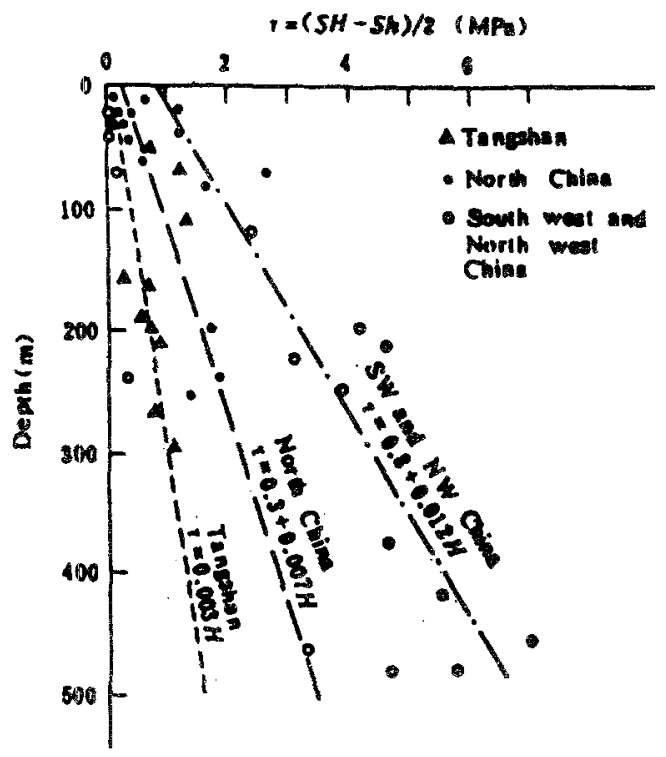

Figure 2

Variation of maximum horizontal shear stresses with depth.

According to observations, the major horizontal shear stress as a function of depth in Southwest and Northwest China can be represented by

$$
\tau=0.8+0.012 H \quad \text { (MPa). }
$$

In North China,

$$
\tau=0.3+0.007 H \quad(\mathrm{MPa})
$$

and in Tangshan region we have

$$
\tau=0.003 H \quad(\mathrm{MPa})
$$

where $H$ is the depth in meters.

\subsection{Depth Variation of the Ratio of the Maximum Horizontal Stress to Vertical} Stress, and that of the Minimum Horizontal Stress to Vertical Stress

According to the data obtained from in situ stress measurements in China, the ratio of the maximum horizontal stress over the vertical stress, $K_{H}=S_{H} / S_{v}$ varies with depth as follows (Fig. 3a)

$$
60 / H+0.8 \leq K_{H} \leq 240 / H+2.0 .
$$

The average variation is

$$
K_{K Y}=150 / H+1.4 .
$$



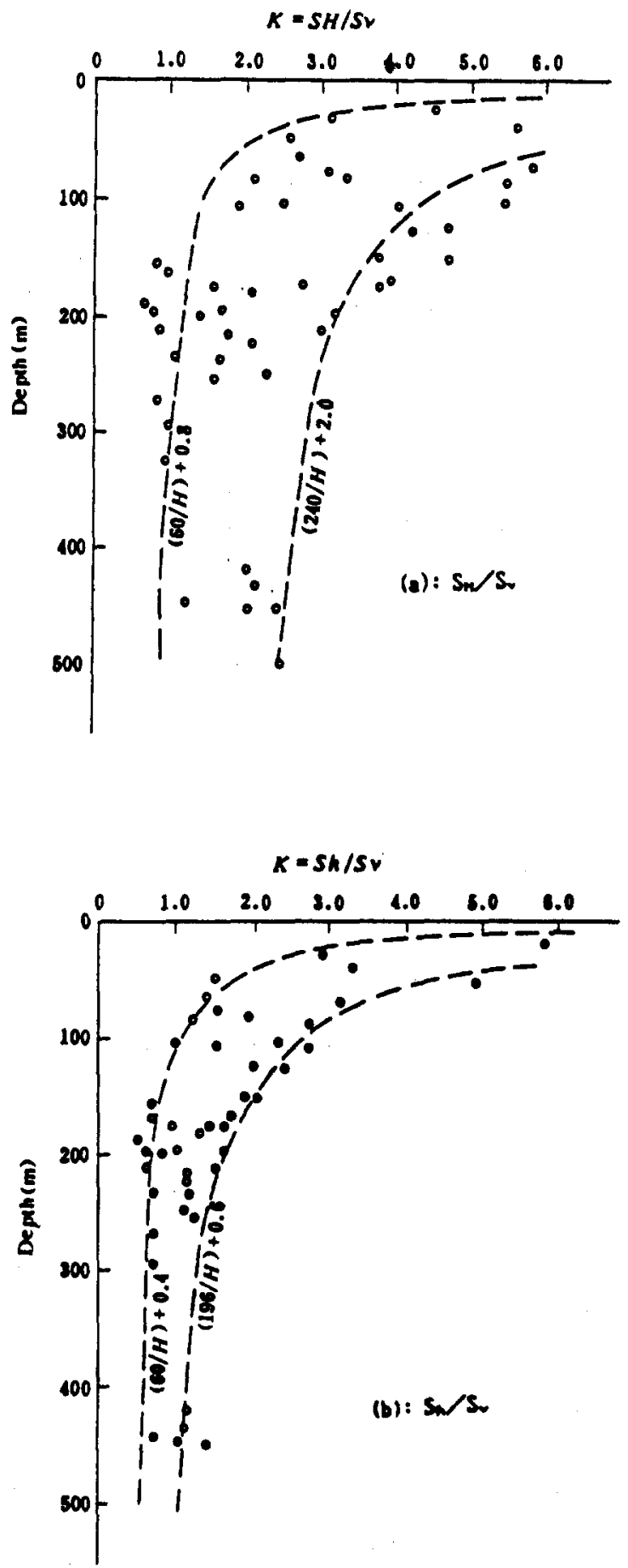

Figure 3

Variation of ratios of the horizontal stress to the vertical stress with depth. (a) $S_{H} / S_{v}$; (b) $S_{h} / S_{v}$. 
The ratio of the minimum horizontal stress over the vertical stress, $K_{h}=S_{h} / S_{v}$, varies as follows (Fig. 3b)

$$
60 / H+0.4 \leq K_{h} \leq 196 / H+0.6 .
$$

The average variation is

$$
K_{h}=128 / H+0.5 .
$$

If we consider the lower limitation, we have $S_{H} \approx S_{v}$ and $S_{h} \approx 0.5 S_{v}$. It can be observed from available data that generally the two horizontal stresses are larger than the vertical one, which is a condition favorable to thrusting, though this may be just a shallow phenomenon. In the deeper part, we have $S_{H} \geq S_{v}>S_{h}$, meaning that the stress state favors strike-slip faulting or even normal faulting.

\subsection{The Directions of the Horizontal Principal Stresses and the Stress Provinces in China}

The stress state in North China has been described in more detail due to the availability of more data. Mt. Taihangshan separates North China into two distinct parts (as shown in Figure 4). East of Mt. Taihangshan, the plain of North China including its surrounding mountainous districts is a broad region with maximum horizontal compressive stress oriented about $\mathrm{E}-\mathrm{W}$. This is consistent with the results from other studies (YAN et al., 1979; XU et al., 1992), and similar to the results of $S_{H}$ from the Japan Islands (TANAKA and OKA, 1979). However, in Shanxi Graben, west of Mt. Taihangshan, there is a sharp change in the direction of $S_{H}$ (Fig. 4).

In South China, south of the EW oriented Qinling-Dabieshan tectonic zone (see Fig. 4), the direction of the principal stress is rather uniform at WNW-NW and consistent with the directions of the $P$ axis obtained from the fault plane solutions (YAN et al., 1979; XU et al., 1992). The boundary is well defined, coinciding with the alignment of Qinling-Dabieshan Mountain.

There are a few in situ stress data in Northeast China. From these data, together with fault plane solutions, we can see that the compressive principal stresses lie predominantly in the ENE direction.

The data coverage in West China is quite sparse. The obtained directions of $S_{H}$ were predominantly NNE, while some trend nearly NS.

The stress states within Southwest China might be related to the lateral spreading of the Qinghai-Tibet Plateau, however, the stress state is rather complicated there.

According to the geomechanics initiated by Lee in 1946 (LEE, 1984), the tectonic traces of the crust always reflect upon the behavior of the crustal stress. However, the tectonic traces on the crust occurred in groups, and each group of the tectonic traces shows a certain manner of tectonic movement and tectonic stress 


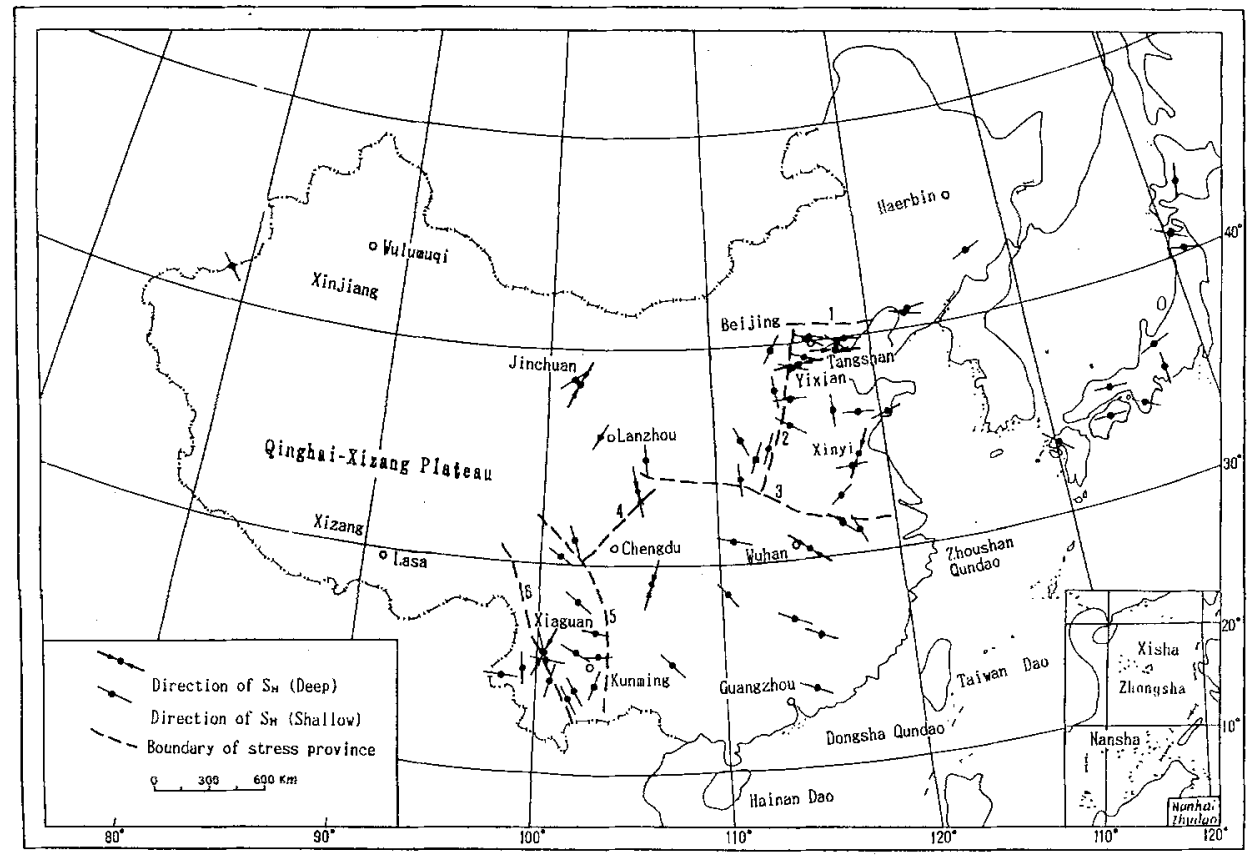

Figure 4

The distribution of the maximum horizontal stress direction in the Mainland China and Japan. The data of in situ stress measurements in Japan are from TANAKA et al. (1979). The data are classified into two groups: shallow (those measured at a depth less than $100 \mathrm{~m}$ ), and deep. 1-Yinshan tectonic zone; 2-Taihangshan tectonic zone; 3-Qinling-Dabieshan tectonic zone; 4-Longmenshan fault zone; 5-Xianshuihe-Xiaojiang fault zone; 6-Langcangjiang fault zone.

field. Studying the activity of the faults in the Great Britain Islands, ANDERSON (1942) considered that the stress which caused the fault to be active was not local, and in a given time, what influenced most regions of the country belonged to the same general stress system. The results of in situ stress measurements reveal that there exist relatively uniform stress distributions in different regions of the continent which can be characterized by principal stresses.

\section{Conclusion}

On Mainland China the rate of increase of the horizontal principal stress with depth is greater than that of the vertical stress. The depth gradients of the major shear stress vary from region to region. The depth gradient of the major shear stress in Western China is almost twice that of Eastern China. Similarly, a more rapid increase of the horizontal stress with depth has been found in Western China than in Eastern China. These observations may reflect the regional differences in tectonic environments. 
It may be observed from the available data that generally the two horizontal principal stresses are larger than the vertical one, a condition favorable to thrusting, although this may be just a shallow phenomenon. In the deeper part, $S_{H} \geq S_{v}>S_{h}$ it seems likely that the stress state favors strike slip faulting or normal faulting.

In Mainland China the horizontal stresses are characterized by strong directionality; the directions of the major horizontal principal stresses are stable and uniform within ceratin broad areas. These stress directions appear to be associated with geological structure as well as current crustal deformation.

The results described here are mainly based on the analyses of the data obtained from in situ stress measurements at shallow depths of $500 \mathrm{~m}$. Whether these results could be extrapolated to the depths of tens of kilometers is at present questionable. For earthquake prediction and geodynamics study, it is essential to carry out in situ stress measurements at deeper levels in the crust.

\section{REFERENCES}

Anderson, E. M., The Dynamics of Faulting (Oliver and Boyd, London 1942).

LEE, J. S., An Introduction to Geomechanics (Gordon and Breach Sci. Publ. Inc., New York 1984).

Li, F., and WANG, L. (1979), Stress Measurements in North China, Acta Geophys. Sin. 22, 1-8 (in Chinese with English abstract).

Li, F., Zhang, J., LiU, P., BI, S., MaO, J., and ZhaO, S. (1985), Deep Stress Measurements in Tanghshan Area, North China Earthq. Sci. 3,115-123 (in Chinese with English abstract).

Li, F., and LiU, G. (1986), The Present State of Stress in China and Related Problems, Acta Seismol. Sin. 8, 156-171 (in Chinese with English abstract).

Li, F., Zhai, Q., BI, S., LiU, P., Zhang, J., and ZhaO, S. (1986), In situ Stress Measurements by Hydraulic Fracturing and Preliminary Results, Acta Seismol. Sin 8, 107-114.

Li, F., Liu, G., XIE, F., Liang, H., Zhang, J., Liu, P., MaO, J., and Qr, Y. (1992), Basic Feature of the Recent Tectonic Stress Field of West Yunnan and Environs, Collected Works of Experimental Field of Earthquake Prediction in West Yunnan Province, Seismological Press, 196-208 (in Chinese).

QI, Y., MAO, J., LiU, P., LI, F., ZhanG, B., ChEN, Y., and LuO, S. (1989), Hydrofracturing Stress Measurements in Ziliujing Anticline near Zigong City, Collected Works of Crustal Structure and Crustal Stress No. 3, Seismological Press, $93-99$ (in Chinese).

TANAKA, Y., and OKA, Y. (1979), Generation Mechanism of Rock Bursts Water-induced Earthquakes under the Tectonic Stress Field, Rock Mech., Japan 3, 17-73.

XU, Z., Wang, S., HuAnG, Y., and GaO, A. (1992), Tectonic Siress Field of China Inferred from a Large Number of Small Earthquakes, J. Geophys. Res. 97, 11867-11877.

Yan, J., Shi, Z., WANG, S., and HuAn, W. (1979), Some Features of the Recent Tectonic Stress Field of China and Environs, Acta Seismol. Sin. 1, 9-24 (in Chinese with English abstract).

(Received September 7, 1994, revised March 29, 1995, accepted April 10, 1995) 